\title{
Hippo signaling does it again: arbitrating cardiac fibroblast identity and activation
}

\author{
Anne Katrine Z. Johansen ${ }^{1}$ and Jeffery D. Molkentin ${ }^{1,2}$ \\ ${ }^{1}$ Department of Pediatrics, Cincinnati Children's Hospital Medical Center, University of Cincinnati, Cincinnati, Ohio 45229, \\ USA; ${ }^{2}$ Howard Hughes Medical Institute, Cincinnati Children's Hospital Medical Center, Cincinnati, Ohio 45229, USA
}

The Hippo pathway is an evolutionarily conserved kinase cascade that is fundamental for tissue development, homeostasis, and regeneration. In the developing mammalian heart, Hippo signaling regulates cardiomyocyte numbers and organ size. While cardiomyocytes in the adult heart are largely postmitotic, Hippo deficiency can increase proliferation of these cells and affect cardiac regenerative capacity. Recent studies have also shown that resident cardiac fibroblasts play a critical role in disease responsiveness and healing, and in this issue of Genes and Development, Xiao and colleagues (pp. 1491-1505) demonstrate that Hippo signaling also integrates the activity of fibroblasts in the heart. They show that Hippo signaling normally maintains the cardiac fibroblast in a resting state and, conversely, its inactivation during disease-related stress results in a spontaneous transition toward a myofibroblast state that underlies fibrosis and ventricular remodeling. This phenotypic switch is associated with increased cytokine signaling that promotes nonautonomous resident fibroblast and myeloid cell activation.

Hippo signaling was first uncovered in Drosophila melanogaster using genetic mosaic screens to search for tumor suppressors, where it was shown to mediate cell proliferation, tissue, and organ size (Xu et al. 1995; Harvey et al. 2003). The signaling pathway includes the upstream kinase Hippo, which is orthologous to mammalian Ste20like kinases $1 / 2$ (Mst1/2) (Fig. 1). Mst1/2 form a complex with Salvador (also known as WW45) that permits phosphorylation and activation of the large tumor suppressor homolog kinases1/2 (Lats1/2) in mammals. Lats1/2 then phosphorylate the transcriptional cofactors Yes-associated protein (Yap) and Taz, preventing their nuclear localization and association with the TEA domain family (TEAD1-4) of transcription factors (Liu and Martin 2019). Inactivation of Mst1/2 or Lats $1 / 2$ allows Yap and

[Keywords: cell state transitions; epigenomics; fibrosis; Hippo signaling; macrophages; myofibroblast; tissue homeostasis; myocardial infarction; single-cell RNA-seq]

Corresponding author: jeff.molkentin@cchmc.org

Article is online at http://www.genesdev.org/cgi/doi/10.1101/gad.332791. 119.
Taz to persist in an unphosphorylated state, permitting translocation to the nucleus, where they interact with TEAD factors to promote expression of proliferative and growth-related genes (Liu and Martin 2019). Changes in cell shape and/or tissue rigidity can also activate Yap/ Taz via mechanotransduction, a critical phenomenon in organogenesis, tissue homeostasis, and regeneration where physical cues from the extracellular matrix (ECM) activate gene expression in a cell-specific manner (Fig. 1; Panciera et al. 2017).

Cardiac fibroblasts (CFs) are the main cell type that synthesize and maintain the ECM in the heart (Khalil et al. 2019). Upon activation by acute injury and/or inflammatory signals, these cells convert to a more synthetic and contractile state known as the myofibroblast that promotes tissue fibrosis and remodeling (Tallquist and Molkentin 2017). During development, CFs are derived from a layer of cells that encapsulates the heart, known as the epicardium (Acharya et al. 2012). Recent studies have shown that inactivation of the Hippo pathway by deletion of Lats1/2 in proepicardial cells prevents formation of CFs, resulting in a grossly abnormal heart (Xiao et al. 2018). Such results could also be extrapolated to suggest that Hippo signaling should also underlie adult tissue fibroblast conversion to myofibroblasts with acute and chronic disease stimuli. Indeed, fibroblasts are activated in injured tissues by inflammatory signals and stretch, stimuli that also broadly lead to Yap and Taz nuclear accumulation (Liu et al. 2015; Piersma et al. 2015; Ramjee et al. 2017). However, direct mechanistic data linking Hippo signaling in CFs to adult disease states was lacking.

In this issue of Genes \& Development, Xiao and colleagues use elegant mouse genetic strategies to mechanistically dissect the role that Hippo signaling plays within adult CFs from both the healthy and ischemic heart (Xiao et al. 2019). To deactivate Hippo signaling, the authors conditionally deleted Lats1/2 genes in CFs (Lats1) 2 CKO) using a fibroblast-specific, adult inducible Cre strategy, which spontaneously activated cardiac fibrosis

(C) 2019 Johansen and Molkentin This article is distributed exclusively by Cold Spring Harbor Laboratory Press for the first six months after the fullissue publication date (see http://genesdev.cshlp.org/site/misc/terms. xhtml). After six months, it is available under a Creative Commons License (Attribution-NonCommercial 4.0 International), as described at http://creativecommons.org/licenses/by-nc/4.0/. 


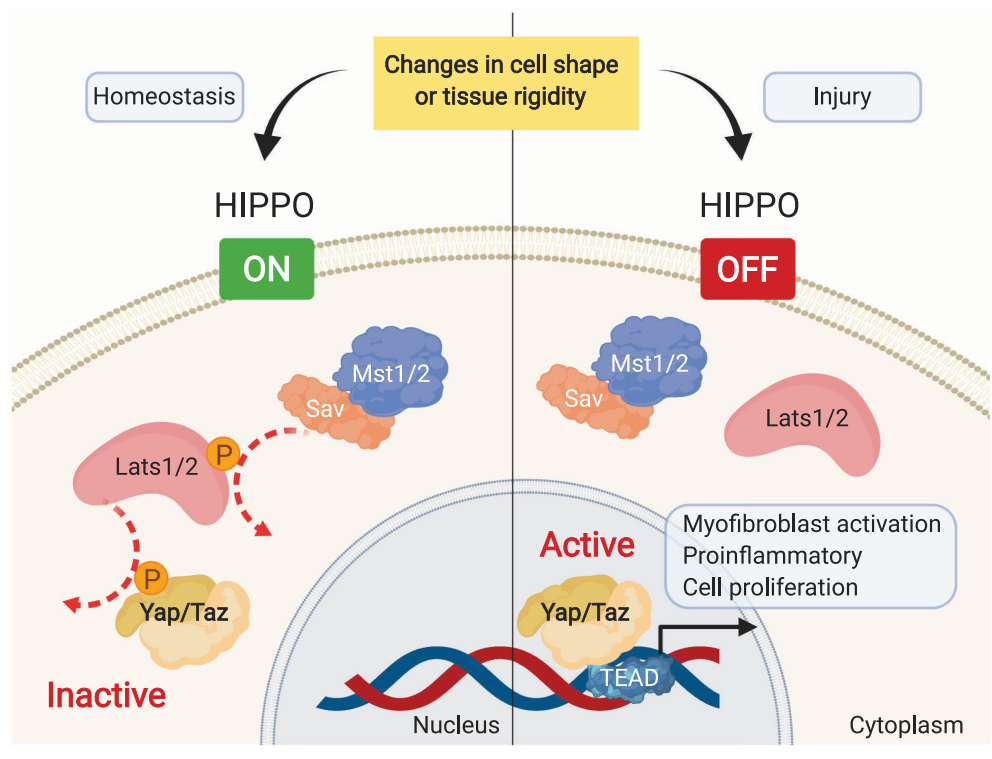

Figure 1. Hippo signaling in cardiac fibroblasts. In the adult heart, Hippo signaling is required to maintain fibroblasts in their quiescent state (left). Upon fibroblast activation, Hippo signaling is switched off, leading to Yap/Taz nuclear localization (right). Downstream from membrane signal transduction and/or stretch sensing, Mst1/2 form a complex with Salvador (Sav) to mediate phosphorylation of the kinases Lats1/2. In turn, Lats $1 / 2$ mediates phosphorylation of Yes-associated protein (Yap) and Taz, which sequesters them in the cytoplasm or leads to their degradation. Unphosphorylated Yap/Taz reside within the nucleus where they interact with TEA domain (TEAD) transcription factors to regulate genes involved in myofibroblast formation and function, as well as induction of inflammatory signals. in the endo- and epicardial regions of the otherwise uninjured heart. Single-cell sequencing analysis revealed unique epicardial, fibroblast, and myeloid clusters in these Lats1/2 CKO hearts. Two of the fibroblast clusters had inflammatory gene signatures, one expressed markers of activated fibroblasts, and four clusters were identified as myofibroblasts that expressed Yap/TEAD target genes. Interestingly, not all the clusters showed a loss of Lats $1 / 2$ expression due to known inefficiency in Cre-mediated recombination, which serendipitously generated an internal control for the unique gene signatures associated with Lats1/2 deletion and constitutive Yap/Taz activity. For example, myofibroblasts had an approximately fivefold increase in gene expression for ligand-receptor pairings, with the expression of ligands known to participate in the wound-healing response. This was further supported by the increased expression of cytokines in the Lats $1 / 2$ CKO hearts, including select chemokines (CCL12, CCL2), colony-stimulating factor 1 , and tissue inhibitor of metalloproteinases-1. In addition to these fibroblast clusters, there was an emergence of seven myeloid lineage clusters unique to the Lats1/2 CKO hearts, suggesting that these altered fibroblasts promote inflammatory signaling.

To identify other gene regulatory networks and cell states, the authors applied a bioinformatic methodology known as SCENIC (Aibar et al. 2017), which first determines genes that are co-expressed with a transcription factor and then performs motif analysis to remove indirect target genes. As expected, TEAD regulons were enriched within the myofibroblast clusters. In addition, regulons associated with endoplasmic reticulum stress and the unfolded protein response were enriched within this cluster. To further analyze Yap target genes, the authors performed HiCHIP, which demonstrated Yap chromatin occupancy within promoters of myofibroblast-associated genes. In addition, Yap was found to predominantly occupy enhancer-enhancer loops and enhancer-promoter loops. Gene ontology analysis of these promoters, which were also detected by RNA-seq analysis, was enriched for pathways associated with inflammation and for activation of the proto-oncogene, Myc.

To elucidate the effect of Lats1/2 depletion in CFs in the setting of disease, mice were subjected to myocardial infarction, which resulted in prolonged CF proliferation and altered scar formation, leading to lethality in all Lats1/2 CKO mice within $3 \mathrm{wk}$. Massons' trichrome staining of the ischemic area revealed less dense, noncompacted collagen content in the Lats1/2 CKO, suggesting that Hippo signaling was necessary for mature scar formation and the fully differentiated function of myofibroblasts.

The report of Xiao and colleagues elegantly shows how Hippo signaling is an integrated component of CF differentiation and activation in the adult mouse heart in normal homeostasis and with injury (Fig. 1), which also suggests the importance of cell-cell interaction in the heart (myeloid, endothelial, and cardiomyocytes). Like all pioneering work, numerous interesting questions arise that will be important to pursue in the future. What is the full scope of physiologic signaling in the nondiseased heart that leads to Hippo activity to maintain Yap/Taz in their inactive state (Fig. 1)? What role does stretch sensing play within the fibroblasts in regulating Hippo signaling versus inflammatory signals through membranebound receptors? More mechanistic investigation of endogenous Hippo signaling in CFs after injury is needed, such as annotating the dynamic regulation of Yap/Taz nuclear localization during myocardial infarction injury and other diseases with chronic fibrosis. There are also data suggesting that Yap/Taz can operate in a Lats1/2-independent manner (Panciera et al. 2017) and that Lats $1 / 2$ can mediate cell signaling beyond restricting Yap/Taz (Furth and Aylon 2017), which future studies of CF should address. Finally, it will be important to consider the development of new therapeutic approaches and ways to temporally activate or inhibit Hippo signaling in CFs to treat longstanding and progressive cardiac fibrotic 
disease states but without impacting the regenerative responsiveness in cardiomyocytes from this same signaling pathway.

\section{Acknowledgments}

We would like to thank Jose Gomez-Arroyo for graphical designs.

\section{References}

Acharya A, Baek ST, Huang G, Eskiocak B, Goetsch S, Sung CY, Banfi S, Sauer MF, Olsen GS, Duffield JS, et al. 2012. The bHLH transcription factor Tcf 21 is required for lineage-specific EMT of cardiac fibroblast progenitors. Dev 139: 2139-2149. doi:10.1242/dev.079970

Aibar S, González-Blas CB, Moerman T, Huynh-Thu VA, Imrichova H, Hulselmans G, Rambow F, Marine JC, Geurts P, Aerts J, et al. 2017. SCENIC: single-cell regulatory network inference and clustering. Nat Methods 14: 1083-1086. doi:10 $.1038 /$ nmeth. 4463

Furth N, Aylon Y. 2017. The LATS1 and LATS2 tumor suppressors: beyond the Hippo pathway. Cell Death Differ 24: 1488-1501. doi:10.1038/cdd.2017.99

Harvey KF, Pfleger CM, Hariharan IK. 2003. The Drosophila Mst ortholog, hippo, restricts growth and cell proliferation and promotes apoptosis. Cell 114: 457-467. doi:10.1016/S0092-8674 (03)00557-9

Khalil H, Kanisicak O, Vagnozzi RJ, Johansen AK, Maliken BD, Prasad V, Boyer JG, Brody MJ, Schips T, Kilian KK, et al. 2019. Cell-specific ablation of Hsp47 defines the collagen-producing cells in the injured heart. JCI Insight 24: e128722. doi:10.1172/jci.insight.128722

Liu S, Martin JF. 2019. The regulation and function of the Hippo pathway in heart regeneration. Wiley Interdiscip Rev Dev Biol 8: e335. doi:10.1002/wdev.335
Liu F, Lagares D, Choi KM, Stopfer L, Marinković A, Vrbanac V, Probst CK, Hiemer SE, Sisson TH, Horowitz JC, et al. 2015. Mechanosignaling through YAP and TAZ drives fibroblast activation and fibrosis. Am I Physiol Cell Mol Physiol 308: L344-L357. doi:10.1152/ajplung.00300.2014

Panciera T, Azzolin L, Cordenonsi M, Piccolo S. 2017. Mechanobiology of YAP and TAZ in physiology and disease. Nat Rev Mol Cell Biol 18: 758-770. doi:10.1038/nrm .2017 .87

Piersma B, de Rond S, Werker PMN, Boo S, Hinz B, van Beuge MM, Bank RA. 2015. YAP1 is a driver of myofibroblast differentiation in normal and diseased fibroblasts. Am J Pathol 185: 3326-3337. doi:10.1016/j.ajpath.2015.08.011

Ramjee V, Li D, Manderfield LJ, Liu F, Engleka KA, Aghajanian H, Rodell CB, Lu W, Ho V, Wang T, et al. 2017. Epicardial YAP/ TAZ orchestrate an immunosuppressive response following myocardial infarction. I Clin Invest 127: 899-911. doi:10 $.1172 /$ JCI88759

Tallquist MD, Molkentin JD. 2017. Redefining the identity of cardiac fibroblasts. Nat Rev Cardiol 14: 484-491. doi:10.1038/ nrcardio.2017.57

Xiao Y, Hill MC, Zhang M, Martin TJ, Morikawa Y, Wang S, Moise AR, Wythe JD, Martin JF. 2018. Hippo signaling plays an essential role in cell state transitions during cardiac fibroblast development. Dev Cell 45: 153-169.e6. doi:10.1016/j .devcel.2018.03.019

Xiao Y, Hill MC, Li L, Deshmukh V, Martin TJ, Wang J, Martin JF. 2019. Hippo pathway deletion in adult resting cardiac fibroblasts initiates a cell state transition with spontaneous and self-sustaining fibrosis. Genes Dev (this issue). doi:10.1101/ gad.329763.119

Xu T, Wang W, Zhang S, Stewart RA, Yu W. 1995. Identifying tumor suppressors in genetic mosaics: the Drosophila lats gene encodes a putative protein kinase. Development 121: 10531063. 


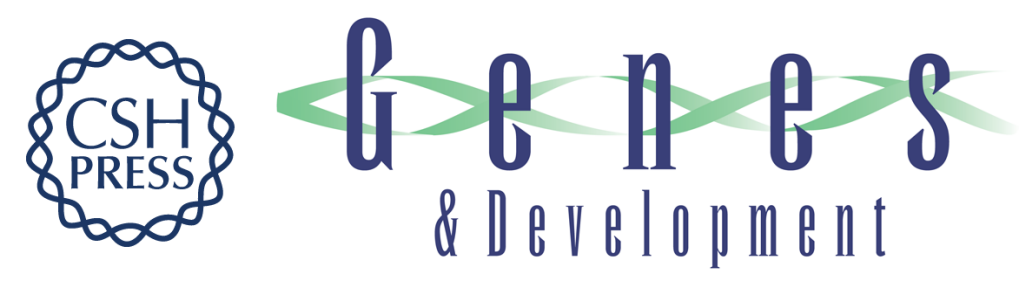

\title{
Hippo signaling does it again: arbitrating cardiac fibroblast identity and activation
}

Anne Katrine Z. Johansen and Jeffery D. Molkentin

Genes Dev. 2019, 33:

Access the most recent version at doi:10.1101/gad.332791.119

\begin{abstract}
Related Content
Hippo pathway deletion in adult resting cardiac fibroblasts initiates a cell state transition with spontaneous and self-sustaining fibrosis

Yang Xiao, Matthew C. Hill, Lele Li, et al.

Genes Dev. November , 2019 33: 1491-1505

References This article cites 14 articles, 3 of which can be accessed free at:

http://genesdev.cshlp.org/content/33/21-22/1457.full.html\#ref-list-1

Articles cited in:

http://genesdev.cshlp.org/content/33/21-22/1457.full.html\#related-urls

Creative This article is distributed exclusively by Cold Spring Harbor Laboratory Press for the first

Commons

License

six months after the full-issue publication date (see

http://genesdev.cshlp.org/site/misc/terms.xhtml). After six months, it is available under a

Creative Commons License (Attribution-NonCommercial 4.0 International), as described at http://creativecommons.org/licenses/by-nc/4.0/.

Email Alerting Receive free email alerts when new articles cite this article - sign up in the box at the top

Service right corner of the article or click here.
\end{abstract}

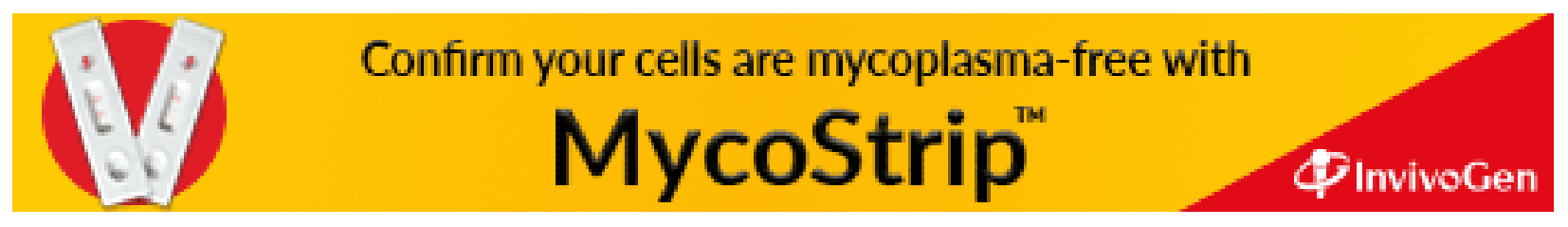

